\title{
Colonización y frontera agropecuaria en Colombia. De la gesta heroica de modernización, hasta el desarraigo forzado y la disminución de nuestra biodiversidad como producto de nuestra búsqueda del desarrollo
}

Fecha de recepción: 20 de mayo de 2011

Fecha de aprobación: 12 de julio de 2011

\begin{abstract}
Ivonne Cueto Gómez
ivcuetog@poli.edu.co

Politécnico Grancolombiano

Comunicadora social con énfasis en Televisión Educativa de la Pontificia Universidad Javeriana, con formación en temas Ambientales y candidata a magíster en Desarrollo Rural. Ha contribuido en el diseño e implementación de proyectos y estrategias de investigación, educación y comunicación para el desarrollo sostenible, en el campo de la educación ambiental y la comunicación para el desarrollo a través del diseño de documentos pedagógicos y de productos audiovisuales en instituciones como la Unidad de Parques Nacionales Naturales de Colombia, Corporinoquía, Señal Colombia - RTVC Radio Televisión de Colombia, el Fondo para la Acción Ambiental, la Corporación para la Protección Ambiental Cultural y el Ordenamiento Territorial, la empresa de Acueducto de Bogotá y algunas otras ONG's de carácter ambiental.

Docente universitaria del área de Desarrollo Sostenible del Politécnico Grancolombiano.
\end{abstract}

\section{Resumen}

Este artículo pretende establecer algunos elementos de análisis de la relación entre el avance de la frontera agropecuaria y los procesos de coIonización en Colombia, como parte estructural de la actual crisis agraria que vive el país. Se abordan a través de un recorrido histórico por diversas etapas, las causas que ocasionaron esos procesos y los elementos comunes que marcan una colonización sin criterios de sostenibilidad como respuesta a una crisis social y económica en una sociedad que ha dejado de lado el sector rural. Ese análisis establece algunas evidencias de que este proceso en la actualidad amenaza la biodiversidad en Colombia y contribuye a acrecentar los fenómenos de violencia que han marcado la historia de este país en las últimas décadas.

\section{Palabras clave}

Colonización, frontera agropecuaria en Colombia, biodiversidad en Colombia, desarrollo.

\section{Abstract}

This article aims to establish some elements of analysis of the relationship between the advance of the agricultural frontier and colonization processes in Colombia, as a structural part of the current agrarian crisis in the country. Through a historical journey through various stages, the causes that led to these processes are addressed and also the common elements that make a settlement without sustainability criteria in response to social and economic crisis in a society that has neglected the rural sector. This analysis provides some evidence that this process threatens biodiversity and contributes to increasing the phenomena of violence that have marked the history of this country in recent decades.

\section{Keywords}

Colonization, Agricultural Frontier in Colombia, Biodiversity, Development. 


\section{Introducción}

La colonización desorganizada y sin criterios de sostenibilidad ha sido una de las características a partir de las cuales la población colombiana ha definido su relación con el territorio. Como una paradoja, a pesar de poseer casi un 10\% de la biodiversidad mundial, la sociedad que ocupa este territorio no ha logrado conciliar las políticas y planes nacionales de desarrollo con la protección y uso sostenible de sus ecosistemas y ha permanecido pasiva frente a las tendencias de avance de la frontera agropecuaria que está marcada por fenómenos como la violencia, el narcotráfico y alta concentración de la tierra.

Después de que a inicios del siglo XIX, las tierras denominadas como "baldías" que representaban áreas de altos grados de conservación, tenían un porcentaje de más del $75 \%$ del territorio nacional, a finales del siglo XIX y comienzos del siglo XX se disparó un fenómeno de colonización que obedecía a la demanda de diversos productos en los mercados internacionales y por ende, a las políticas gubernamentales de una nación recién conformada que requería promover su crecimiento económico y que, para ello, se sustentó en tres objetivos específicos: la oferta gratis de tierras, la atracción de inmigrantes extranjeros y la construcción de una red vial que diera paso a nuevas regiones (Legrand, 1988).

Ya en el siglo XXI, a pesar de la gran diversidad de ecosistemas que caracteriza a este país, se puede afirmar que el porcentaje de zonas sin procesos de colonización se ha disminuido drásticamente a menos del $20 \%$ del territorio nacional. Si consideramos que aproximadamente el $11 \%$ de nuestro territorio está destinado a zonas de conservación, esa cifra muestra el rápido proceso de colonización de territorios conocidos como baldíos y por ende, un vertiginoso avance de la frontera agrícola con altos niveles de deforestación.

El caso de Colombia refleja una realidad compartida por la mayoría de países latinoamericanos, en donde se estima que cerca de la mitad de la deforestación se ha producido en los últimos 60 años. Como resultado, se demuestra una presión creciente sobre los ecosistemas naturales que varía en función del desarrollo económico, las condiciones sociales y los procesos políticos de planificación de uso de la tierra. Estos elementos se han implementado a través modelos operacionales de reforma agraria que nunca han dado solución a los problemas estructurales del sector agrario y al contrario, han incentivado procesos de colonización sin un adecuado planteamiento de políticas de desarrollo rural, promoviendo procesos de colonización espontánea, que de manera paralela han desencadenado un escenario crítico, en el cual es evidente un alto nivel de concentración de la tierra por parte de algunos pequeños sectores de la sociedad y muy pocas alternativas de empleo, ingresos y posibilidades de subsistencia para el sector de los pequeños y medianos campesinos.

Una mirada histórica de estas dinámicas de colonización nos permite comprender algunos de estos procesos para dividirlos en dos grandes etapas: la colonización de vertientes de cordillera de una nación con un inmenso afán por modernizarse y una fase determinada por el discurso del desarrollo que después de la segunda mitad del siglo XX 
ha estado marcada por conflictos sociales heredados de la fase anterior, y que en su afán de crecimiento económico, ha producido el desarraigo forzado de muchos campesinos que cada día engordan más las cifras de pobreza, desempleo y marginalidad en nuestro país.

Finalmente se establecen algunas evidencias de las tendencias actuales de la colonización, los conflictos que la generan y los impactos a nivel ambiental, social y económico que trae. Este trabajo expone algunas alternativas que nos permitirían concebir un tipo de desarrollo diferente, fundamentado en lo que Antonio García denomina una nueva ciencia social crítica (Modelos operacionales de reforma agraria y desarrollo rural en América Latina, 1982), que permita modificar la histórica cadena de desbalances en la distribución de la tierra en nuestro país y el acelerado deterioro que hemos causado en nuestros ecosistemas,

\section{COMIENZA LA GESTA DE COLONIZACIÓN. Recorrido Histórico. Análisis de Causas y zonas donde se han desarrollado procesos de colonización}

Las tierras que han sido fruto de los procesos de colonización se han convertido en pilares de la estructura económica y social del país. Inicialmente el proceso de poblamiento de lo que conocemos hoy como Colombia se dio desde las tierras de los altiplanos hacia las "tierras calientes". En los inicios de nuestra historia, los altiplanos presentaban mejores condiciones para la reproducción de la sociedad occidental, sobre todo desde el punto de vista climático, lo que era muy valorado por la sociedad criolla tanto colonial como republicana. Las zonas tropicales constituyeron un desafío para los colonizadores, David Arnold citado por Palacio (2006) menciona que mientras para Cristóbal Colón el trópico era una especie de Edén, y a comienzos del siglo XIX Humboldt también compartía esa opinión al "celebrar esa exuberante naturaleza tropical", a finales de ese mismo siglo las zonas tropicales de Colombia eran consideradas "como una tierra de enfermedades, gente perezosa, regiones salvajes y nativos caníbales" (Palacio Castañeda, 2006). Por esa razón, la colonización inicial se dio sobre las tierras frías o templadas que son más fáciles de domesticar para reproducir los modelos de uso de la tierra de los europeos.

La verdadera ampliación de la frontera agrícola y la sucesiva desaparición de zonas de bosques primarios, se inició en la época de la república, donde los valles interandinos que eran las zonas ancestralmente habitadas por las comunidades indígenas, se convirtieron en grandes extensiones de tierra concentradas en pocas manos, que se transformaron en régimen de Haciendas. Pero ya hacia mediados y finales del siglo XIX, las tierras calientes adquirieron un valor diferente debido a la aparición de la economía tabacalera, lo cual empezó a dinamizar una nueva colonización hacia zonas de bosques húmedos tropicales. En efecto, aumentó la población y muchos de los campesinos que habitaban estas haciendas, comenzaron a buscar nuevas tierras en las cuales dejaran de ser simples siervos para poseer un 
pedazo de tierra, lo que dio origen a los primeros conflictos agrarios de los años 20 del siglo XX.

Esa excesiva concentración de la tierra y por ende su mala distribución, la subutilización de la misma y la existencia de insuficientes oportunidades de empleo en otros sectores de la economía, generó en forma creciente el desplazamiento de esa población marginada hacia aquellas áreas alejadas del desarrollo. Luego de que se dieran las primeras zonas de colonización en los valles interandinos y de que se terminara la ocupación de las vertientes de estas montañas "el afán colonizador se volcó sobre las selvas tropicales, regiones de baja capacidad productiva y de alta fragilidad ecológica" (Instituto Colombiano de Reforma Agraria, 1985). Vista desde el Estado, ese tipo de colonización se denominó colonización espontá$n e a^{l}$, "caracterizada por una agricultura de subsistencia, antecedida de un aprovechamiento parcial, controvertible y poco sostenible de los recursos forestales" (Instituto Colombiano de Reforma Agraria, 1985). El proceso generalmente se inicia sin dirección ni planificación y, en términos generales, sin el apoyo institucional del Estado. En ese proceso fue suficiente para los colonos encontrar tierras que tuvieran los suficientes recursos que les permitieran sobrevivir, tales como agua, animales para cazar, ríos que garantiza-

Según el INCORA, 1985, se define la Colonización espontánea como aquella en que el proceso de migración y posterior asentamiento, se realiza de forma independiente y voluntaria sin intervención estatal. Sus protagonistas carecen de medios económicos, no disponen de capacidad técnica y no tienen ningún tipo de servicio. ran la pesca, bosques ricos en maderas y tierras con aparente fertilidad.

Es a partir de esto que empieza una nueva avanzada colonizadora que según Darío Fajardo tiene unas peculiaridades que vale la pena destacar:

el ciclo "migración - colonización - conflicto - migración”, que traslada a muchos de sus actores, inclusive, a través del tiempo y el espacio, como elementos constantes en el proceso de la colonización y que detrás de ellos lleva y reproduce las estructuras agrarias y las contradicciones propias de ellas, prácticamente a todos los rincones de la frontera agricola (Fajardo, 1989).

Transcurridos los años y con un énfasis mayor en la segunda mitad del siglo XX se han desplazado enormes contingentes de población en una dinámica de colonización que ha sido diversa dependiendo del lugar geográfico específico donde se produzca, los actores, y las motivaciones. Estímulos que responden inicialmente al comportamiento de los mercados internacionales que impulsan la explotación y que propiciaron bonanzas económicas tales como la extracción cauchera en la Amazonía, la fiebre del oro en el noreste antioqueño y la Orinoquía, la extracción de quina, tagua, maderas, pieles y luego empiezan a incluirse otro tipo de elementos como la violencia que se recrudece desde los años 50, la crisis de la estructura agraria minifundio latifundio, la falta de alternativas como la reforma agraria, la ausencia de asistencia técnica, la más reciente historia de la irrupción de los cultivos ilícitos en gran parte del país, hasta los desplazamientos forzados de miles de campesinos que 
tienen que buscar distintos horizontes para huirle a las nuevas formas de violencia que han surgido en los últimos años.

Del mismo modo, la colonización ha sido un factor determinante en la creación y expansión de la frontera agrícola en nuestro país, pero hay que reconocer que en cada etapa histórica de su conformación, transformación y obedeciendo también a las políticas de desarrollo nacional, han existido unas características y condiciones concretas que determinan aspectos sociales, económicos y políticos de nuestra configuración como nación. Por esta razón, es necesario hacer un análisis sobre los tipos de colonización que se han dado y debatir cómo algunos de éstos incluso han hecho parte de los procesos de intento de reformas agrarias en Colombia. Teniendo en cuenta que la gran mayoría de estos procesos se han dado de manera no planificada, surgen varias hipótesis sobre la manera en que han contribuido con la ampliación de la frontera agrícola en la mayoría de zonas de nuestro país, lo que ha traído consigo la degradación de un elevado porcentaje de nuestros bosques y áreas naturales.

De esta manera, es necesario ver cómo algunos de estos elementos son recurrentes en los diversos procesos de colonización en Colombia y cuáles han sido los impactos sobre nuestro patrimonio natural en ese desbordado crecimiento de la frontera agropecuaria.

\section{Primeras oleadas de colonización}

Las primeras oleadas de colonización que iniciaron en los tiempos de la Conquista española se dieron predominantemente por los valles y cordilleras andinas y las llanuras del Caribe, buscando principalmente el acceso a recursos minerales como oro y plata, mano de obra indígena y finalmente tierras que les garantizaran la producción de alimentos para empezar los primeros asentamientos y garantizar la supervivencia de sus poblaciones. Las características de la Conquista definieron un tipo de concentración de la propiedad que de manera desbalanceada afectaba a los indígenas, mestizos y blancos pobres quienes empezaban a conformar las bases del campesinado colombiano.

A finales del siglo XVIII, según Darío Fajardo (1989), diferentes regiones que componían el territorio del Reino de Granada, sirvieron de marco para la estructuración de sociedades diferenciadas, en las cuales el patrón común lo constituyó la concentración de la propiedad territorial. A continuación en el periodo de la Independencia, la forma de tenencia de la tierra era heredada en forma de grandes haciendas que simplemente cambiaban de dueños y quedaban en manos de los criollos de las clases altas. Por consiguiente, los tradicionales sectores pobres de la población siguieron en sus papeles de servidumbre y se establecieron figuras de trabajo de la tierra como la aparcería. Durante el tiempo posterior al siglo XVIII hasta el siglo XIX, la población aumentó y se intensificó la producción de diversos productos que eran exportados a Europa y Estados Unidos, lo cual generó una gran presión sobre las zonas agrícolas expandiendo su frontera en las regiones de ladera de las zonas andinas.

El más conocido proceso de colonización de este tipo fue el que se presentó en la zona de Antioquia que se inició desde el siglo XVIII con la fuerte actividad de explotación del oro, "Atraídos por 
las leyendas de fabulosas riquezas ocultas y las noticias de hallazgos efectivos, los primeros conquistadores fueron seguidos bien pronto de numerosos inmigrantes vascongados y asturianos" (Parsons, 1997, p. 22). Esta provincia, según Parsons que hasta el final del período Colonial se hallaba en un evidente atraso económico y cultural, no tenía una agricultura desarrollada ya que se encontraba totalmente descuidada por las minas y el comercio que era evidentemente estacionario.

Fue hasta finales del siglo XVIII que esta empobrecida zona selvática comenzó una transformación en un estado vigoroso donde se empezaron a crear nuevos establecimientos agrícolas y se ofrecieron bonificaciones por la introducción de nuevos cultivos: "Al finalizar el siglo XVIII la producción de oro y la inmigración habían descendido agudamente" (Parsons, 1997, p. 27). El empuje que se le dio a la agricultura contribuyó a la primera expansión de importancia de los pobladores antioqueńos hacia las vertientes vacías y montañosas del sur y suroeste a comienzos del siglo XX. Allí se dio el auge del café como una fuente de mayor riqueza que dio inicio a una nueva configuración de uso del territorio en esta región. Los trabajadores que llegaron a estas grandes haciendas cafeteras, sobre todo en el municipio de Fredonia, que es donde comenzaron las grandes plantaciones, luego se convertirían en los nuevos colonos de las zonas del sur y del occidente y además en los encargados de divulgar sus conocimientos sobre el cultivo del café para que éste se replicara en las nuevas zonas.

La colonización que se dio a partir de los años 20 del siglo XX, se realizó hacia las zonas del Chocó, las tierras del Sinú, el Valle del río Nus y la zona de Turbo, Dabeiba y Necoclí con el empeño de los antioqueños en construir una carretera que les abriera una salida al mar. Autores como Parsons a firman que "'Después de los años 20 las selvas que quedaban fueron cayendo bajo las hachas de los colonos sinuanos... En 1930 un visitador fiscal mandado por el Gobernador de Antioquia describió la cuenca del rio Sinú como totalmente desmontada" (Parsons, 1996). Este autor menciona que se establecieron incentivos para los colonos a través de una ley, en 1931, que les prometió casa, médico, 50 hectáreas de tierra, matas de cacao y banano, semillas de yaraguá o guinea y el préstamo de una vaca lechera. El impacto de esta colonización fue reflejado en el censo de 1964 del Servicio Nacional de Erradicación de la malaria (SEM) donde se reportó una población de 25.900 habitantes para el nuevo municipio de Arboletes y otras 6.800 personas que se calculaba vivían en el distrito del río Mulatos dentro de la jurisdicción de Turbo, luego de que en 1929 la misma población había tenido menos de 2.500 habitantes. Este aumento en la población refleja cómo en la zona de Urabá los agricultores jugaron un papel importante en la transformación de la selva en pastos y rastrojos que fue motivada por la construcción de la carretera al mar.

Para el caso de la colonización antioqueña, la frontera agrícola a mediados del siglo XX aún no se había desbordado y se constituía en un cinturón que se consideraba de territorios productivos $\mathrm{y}$, de alguna manera, promisorios para extracciones y cultivos. En consecuencia este fenómeno de la colonización fue favorecido por decretos y leyes que impulsaron a antioqueños y algunos costeños de las zonas 
del Sinú y del departamento de Córdoba, a ir apropiándose de extensas zonas. Estas nuevas propiedades iban desde las 100 hasta las 500 hectáreas, y generalmente fueron convertidas en zonas de ganadería extensiva: "El modelo inicial de la colonización antioqueña se modificó posteriormente dando paso a procesos de concentración de la propiedad." (Fajardo, 1989.) Se articuló la gran concentración de tierras en pocas manos con el control político ejercido regionalmente por los gamonales quienes se convirtieron en los grandes capitalistas que luego le darían impulso a la industrialización de la región antioqueña. En consecuencia ya en los ańos 60 se evidenciaba una gran ampliación de la frontera agrícola en esta zona y el esfuerzo de construir nuevas vías de penetración para ayudar a los pequeños agricultores en la colonización de las tierras montañosas.

Por esta misma época con la creación del Incora (1961) se impulsaron varios decretos que dinamizaron la expansión se dio sobre diferentes regiones, motivada por el Estado:

Si bien el Estado trató de dar un ordenamiento legal al proceso colonizador, la misma distribución inequitativa de la tierra, produjo un efecto multiplicador de ocupación espontánea en áreas del Caquetá, Putumayo, Arauca y Meta. En desarrollo de estas necesidades de carácter social, el colono motivado por cualquier espejismo, comenzó un proceso de desplazamiento hacia esas regiones apartadas, atraido por la exuberancia y aparente fertilidad, ignorando totalmente la fragilidad del ecosistema, la cual sólo pudo comprobarse cuando se adelantaron en ellas prácticas de cultivos propios de las zonas andinas (Gómez Merlano, 1985, p. 9).

Este tipo de colonización impulsada por el Estado empezó a evidenciar ciertos conflictos sobre las tierras entre aquellos que contaban con todos los medios para realizar ese proceso (mulas, trabajadores, herramientas y alimentos) y aquellos que eran contratados como taladores de las nuevas regiones y que luego se convertían en los arrendatarios de los poseedores de la tierra.

Cuando se creó el Instituto Colombiano de Reforma Agraria, éste pretendía dirigir y orientar el proceso colonizador, sin tener en cuenta toda la herencia de los problemas generados por la colonización espontánea que Alfredo Molano (1987), define como una colonización de base campesina similar en sus características más importantes a la dada en otras zonas del país, que se posibilitó por la denomina rigidez de la estructura dual del latifundio y del minifundio que se venía presentando y por la floreciente penetración de las relaciones capitalistas en el campo y las políticas colonizadoras de instituciones gubernamentales que habían creado asentamientos de colonización dirigida ${ }^{2}$. De esta manera se propuso la gestación de varios proyectos de colonización orientada en la cual, sin limitar la

Entendiendo ésta como aquella que se produce cuando el asentamiento de los colonos es el producto de una decisión del Estado y en consecuencia, dispone de un Plan de desarrollo que incluye selección de áreas, de familias, tipos y sistemas de explotación, suministros de servicios, infraestructura y organización de la comunidad.(Instituto colombiano de Reforma Agraria, 1985, p. 10-11; Maldonado, Gallón, \& Gutiérrez). 
iniciativa de los colonos, el Estado contribuían a la creación de condiciones técnicas, sociales y económicas, que garanticzaran el logro de un asentamiento más eficiente, un racional aprovechamiento de los recursos naturales, una mejor organización de la comunidad y una ordenada y más justa distribución de la tierra (Instituto Colombiano de Reforma Agraria, 1985) que se concretaban en diferentes en zonas como el Caquetá, Putumayo y Guaviare.

Es evidente que los colonos en aquel entonces no tenían los conocimientos sobre los impactos que traería la ampliación de la frontera agrícola en esas nuevas zonas de colonización, pero tampoco el Estado conocía las características fundamentales de los ecosistemas de las zonas selváticas y "dentro de una teoría facilista, consideró que la colonización espontánea podría ser una alternativa viable para buscar alguna solución a los conflictos de tenencia de la tierra que ya se presentaba en el interior del país" (Gómez Merlano, 1985, p. 9) como una válvula de escape para no tener que ocuparse de los problemas de la estructura agraria, de esa manera desde 1960 se convirtió en el principal promotor de esta colonización que modifica vastas zonas del territorio nacional.

\section{INICIOS DE UN} DESARRAIGO FORZADO. Colonización de selva, Ilanos y sabana y su relación con la violencia

La relación que existe entre los procesos de colonización y la violencia que ha caracterizado la historia de nuestra sociedad a partir de la segunda mitad del siglo XX y en lo corrido del siglo XXI, tiene sus orígenes en un sin número de desigualdades sociales que se han reiterado en diferentes épocas con respecto a la tenencia de la tierra en Colombia. Un ejemplo de esto se evidencia en la explicación que realiza Catherine Legrand sobre la manera en que se dio la colonización donde afirma que el campesino se apropia de algunos terrenos que empieza a cultivar y "Una vez que el terreno ha sido domesticado aparece en escena el empresario territorial que llega a disputarle el título de propiedad sobre esa parcela al colono, lo hace así por dos razones: en primer lugar, porque para entonces la tierra ya es netamente productiva $y$, en segundo, porque apenas hay mano de obra disponible en las fronteras de colonización por lo cual cuando el empresario arrebata la tierra al colono espera que este se quede en la parcela como arrendatario, en otras palabras, sometido a otros lazos de dependencia" (1988).

En otras palabras han imperado los históricos patrones de concentración de tierras, en los cuales se ha favorecido a los latifundistas para que cada vez puedan acumular mucho más capital, mientras que los pequeños propietarios han sido despojados de sus predios, aumentando estas desigualdades. Las inconformidades frente a estos patrones de distribución de la tierra fueron aglomerando a algunos campesinos que dieron origen a varias movilizaciones y conflictos que se agudizaron con la Ley de Tierras de 1936. Esta ley causó la expulsión de campesinos, aparceros y arrendatarios de las haciendas y propició la destrucción de grandes zonas de bosque para demostrar la posesión de la tierra (Márquez, 2001). 
Con esta expulsión, además de liberar mano de obra para las nacientes industrias de las pequeñas ciudades que existían, se originaron nuevos fenómenos de violencia.

En consecuencia surgieron entonces los primeros movimientos campesinos de autodefensa. Estas primeras agrupaciones que proclamaban el derecho a la tierra fueron perseguidas por el Gobierno, que pretendía extinguir lo que en esa época se denominó como "repúblicas independientes", y que eran vistas como focos de comunismo que se debían erradicar. Alfredo Molano denomina a este proceso colonización armada, que se vincula indisolublemente con los procesos de violencia agraria ocurridos particularmente en el nordeste del Tolima, en la región del Tequendama y en Cundinamarca, desde el segundo decenio del siglo XX (1987). Este autor reconstruye el proceso masivo de emigración organizada en el mencionado período de la violencia, desde estas regiones andinas hacia el cañón del río Duda y su posterior expansión hacia el río Guayabero, el alto Ariari, El Pato, el alto Caguán y la Sierra de la Macarena. Como resultado, el campesino que se establecía en estas zonas, evidenciaba formas de organización social sui géneris y una dirección política muy particular, factores decisivos que dieron origen al posterior surgimiento de un grupo guerrillero como las FARC en esas zonas de colonización.

Las múltiples estrategias para perseguir a estos campesinos dieron origen a enfrentamientos que se recrudecieron para empezar uno de los procesos de más violencia del siglo XX que adquirió tintes políticos y que se denominó la guerra partidista. Esta guerra dio paso a que se iniciara un proceso de colonización donde los campesinos venían de las zonas de violencia y/o de minifundio de la región Andina, en búsqueda de tierra para poseer y explotar establemente y de seguridad para sus vidas, la de su familia y la de sus bienes, lo que se convirtió en una obsesión predominante (Mora, Cubides, \& Jaramillo, 1987). Es así como la violencia dio origen a varias olas migratorias en departamentos como el Guaviare, $\mathrm{Ca}$ quetá y Putumayo.

A diferencia de esto, los procesos de colonización en la Amazonía colombiana presentan características particulares en términos de la forma como han configurado los imaginarios en sus pobladores, razón por la que debe abordarse su análisis desde un enfoque diferente a las colonizaciones agrícolas o al esquema tradicional de los modelos de las economías campesinas en otras regiones del país.

En las dinámicas que generan estos procesos de colonización se presentaron conflictos por la manera en que se han reproducido formas de uso de la tierra propias de las zonas andinas y por la generación de nuevas dinámicas sociales debido a las particularidades de estos espacios amazónicos. Las condiciones precarias en estos frentes de colonización y la baja productividad de sus suelos facilitaron la inserción en estas regiones de la producción de cultivos ilícitos desde comienzos de los ańos 70. La violencia asociada con éstos, abrió paso a la presencia de las organizaciones insurgentes, las cuales entraron como apoyo de los pequeños productores en alianzas que han logrado continuidad en el tiempo, así como también la construcción de la base social para el proyecto subversivo (Fajardo, 2002). 


\section{LA COCA, DINAMIZADOR DE NUEVOS DESARRAIGOS. Colonización por el auge de la coca}

En la década de los sesenta existieron varios factores que contribuyeron con que el proceso de colonización sufriera un notable incremento. Algunas de las causas fueron: aumento demográfico en los valles interandinos del interior del país, la no implementación de una reforma agraria que mediara en la contradicción latifundio-minifundio, de la subdivisión del minifundio por herencias en pequeñas porciones de tierra y la falta de asistencia técnica dirigida al pequeño productor (Vieco, 1995), elementos que de haber sido tenidos en cuenta se hubieran podido acrecentar los ingresos y mejorar el nivel de vida del sector rural. Como contradicción a todo este panorama, durante esta década y la posterior, la situación fue aprovechada de tal manera que permitió el auge de economías ilegales en las zonas más apartadas del país y al mismo tiempo la guerrilla motivó la colonización rápida de muchas de estas regiones, colonización que en algunos casos se dio de manera armada, como la que se presenta en el Guayabero, el rio Ariarí y la región del Guaviare.

En este escenario entraron a jugar los capitales internacionales de la droga que vieron en estas zonas marginadas del Estado en todos los campos, inclusive el militar, las condiciones perfectas para establecer la producción y comercialización de la economía ilegal de la coca (Trujillo \& Castaño, 1992). Con este aumento de dineros ilegales, inicialmente producto de la marihuana y luego de la coca durante los años 70 y 80 surgían pueblos con una velocidad impresionante. Luego, a mediados de la década, por la sobreoferta de coca fueron desapareciendo con la misma velocidad con que surgieron. Este fenómeno se presentó en zonas como el Putumayo, el Caquetá, el Guaviare y algunas regiones de los Llanos Orientales.

A partir de los años 80 , el narcotráfico le otorgó unas características nuevas al proceso de colonización, ya que su principal objetivo era comprar tierras con el fin de lavar y legalizar algunos de los dineros que provenían del narcotráfico (Vieco, 1995) pero además de una clara intención de tener el dominio territorial sobre extensas zonas del territorio nacional generalmente en regiones de colonización y/o en zonas muy productivas agropecuariamente.

Para complementar este análisis es importante tener en cuenta los aportes que han realizado autores como Juan José Vieco, quien menciona que la experiencia de la región del Magdalena Medio es una de las más ilustrativas y conocida de las nuevas formas que adquiere el conflicto en otras zonas de colonización debido a la irrupción del narcotráfico y que terminan por mediar, regular e impulsar el proceso de colonización que se da en la actualidad. Este tipo de colonización se da en zonas como el Urabá y Córdoba. Esta nueva manera de realizar los procesos de colonización evidencia el encuentro entre diversos fenómenos que van más allá del problema de la tenencia de la tierra: la violencia originada por la irrupción del narcotráfico y del fenómeno paramilitar en las regiones de colonización, su enfrentamiento con 
la guerrilla ha logrado crear una nueva forma de organización espacial en la regiones de colonización (Medina, 1990). Este fenómeno se dio gracias a que la guerrilla, que tenía el control sobre estas zonas y ejercía un dominio tanto político como militar sobre la población regional, perpetró varios excesos con ganaderos y comerciantes con poder político y económico pero también con campesinos, indígenas, colonos y población en general, lo que finalmente condujo a que el narcotráfico encontrara el ambiente propicio para adquirir propiedades en forma violenta e ir conformando ejércitos de sicarios armados que fueron desterrando de muchas regiones la presencia guerrillera. Mediante un exterminio masivo e indiscriminado de la población civil en las zonas donde había presencia guerrillera, el narcotráfico y los paramilitares, con apoyo de sectores del Ejército y la Policía, erradicaron la presencia guerrillera y ocasionaron un éxodo de la población campesina (Vieco, 1995).

Sin importar que en este conflicto murieran millones de colombianos, los paramilitares consolidaron su poder territorial, repoblando las regiones abandonadas con campesinos aliados con los cuales concentran todo el poder territorial para proteger su negocio de la coca y al mismo tiempo arraigar su peso político lo que les ha permitido influir en la desaparición de movimientos políticos y sociales no respaldados por ellos y tener una gran influencia en la elección de alcaldes y dirigentes políticos de las regiones en las cuales tienen control territorial (López Hernandez, 2010).

Aunque se han dado pasos en el desmantelamiento de los grupos paramilitares, estos se han consolidado políticamente y a través de técnicas de miedo, atemorizan a la población que conoce de sobra lo que significa la presencia de estos grupos en regiones marginadas del territorio nacional.

El gran poder territorial que adquirió el narcotráfico en las zonas de colonización es notorio en torno a áreas que cuentan con alguna infraestructura e inversión del Estado, principalmente a través de infraestructura física y vial o que cuenta con perspectivas turísticas o de los llamados mega proyectos como construcción de represas o hidroeléctricas.

Las consecuencias de la colonización en las zonas andinas y la que se da en zonas de selva tropical es evidentemente opuesta a los resultados de la colonización reciente en lo que antiguamente fueron los territorios nacionales. En la primera pese a los desequilibrios en cuanto a tenencia de la tierra, acceso a tecnologías, etc. Se ha logrado que se consoliden sistemas agrarios que en buena parte de estas regiones son el motor de las economías locales y se consolidan internacionalmente. Pero en las zonas de colonización reciente aún existen grandes problemáticas. Entre las principales podemos mencionar la imposibilidad de acceder a créditos o programas de gobierno debido a la ilegalidad de buena parte de los predios por encontrase bajo la figura de protección de Zona de Reserva Forestal, a esto se suma la falta de presencia de las entidades Estatales para garantizar la cobertura de Servicios Básicos, el conflicto armado como elemento que ha trastornado la construcción social de la mayoría de estos poblados, la persistente presencia de bonanzas extractivistas, por solo mencionar algunos de los elementos que hacen particular a este proceso. 
DESARRAIGOS

TRANSFORMADOS EN

ÉXODOS Y EXPANSIÓN DE LA FRONTERA AGRÍCOLA

EN LA ACTUALIDAD. Uso del suelo en la actualidad. Impactos a nivel ambiental, social y económico

Según un informe especial preparado por el diario El Espectador denominado "El país de los desterrados" (Maldonado, Gallón, \& Gutiérrez) en la actualidad Colombia posee 114 millones de hectáreas, de las cuales el $44,6 \%$ es decir 50.900.000 hectáreas, corresponden a zonas rurales que basan su economía en actividades como agricultura, siembra agroforestal y ganadería. Como una coincidencia siniestra, esas mismas zonas son el escenario de la guerra sin sentido que lleva asolando varias décadas a Colombia y que ha ocasionado que 3'300.000 campesinos hayan sido desplazados de sus tierras, llegando a convertirse en un éxodo masivo. En el año 2010, 750.881 familias aparecían registradas como desplazadas ante el gobierno nacional. Los informes de las organizaciones estatales hablan de que 3.700.000 hectáreas han sido abandonadas en medio de este conflicto, pero según algunas organizaciones de la sociedad civil se calcula que la cifra podría llegar hasta 5.500 .000 hectáreas.

Este contexto hace parte de un panorama que evidencia tanto la crisis del sector agrícola, como el peligro que representa el avance de zonas destinadas a actividades ganaderas y otras tantas dedicadas a la producción de cultivos con fines ilícitos en zonas de conservación de la biodiversidad del país.

La guerra en las últimas décadas ha dejado como secuela un aumento evidente en los niveles de concentración de la tierra y un evidente cambio en los usos que se le están dando a esta. Es importante preguntarse qué porcentaje de las 5.500.000 hectáreas han quedado en manos de los violentos, de los narcotraficantes y cuáles en manos de grandes latifundistas. En los procesos de restitución de tierras promovidos en los últimos años, hasta hoy se han entregado 17.000 hectáreas, cifra insignificante para las 480.000 familias que esperan recuperar lo que la guerra les ha quitado. Para poder hacerse a una idea sobre en manos de quién se encuentra esa tierra, es interesante ver cuál es el uso que se le está dando al suelo en Colombia y analizar qué relación tiene este fenómeno con las nuevas zonas destinadas a la colonización. 
Gráfica 1. Vocación de la tierra en Colombia y su uso actual

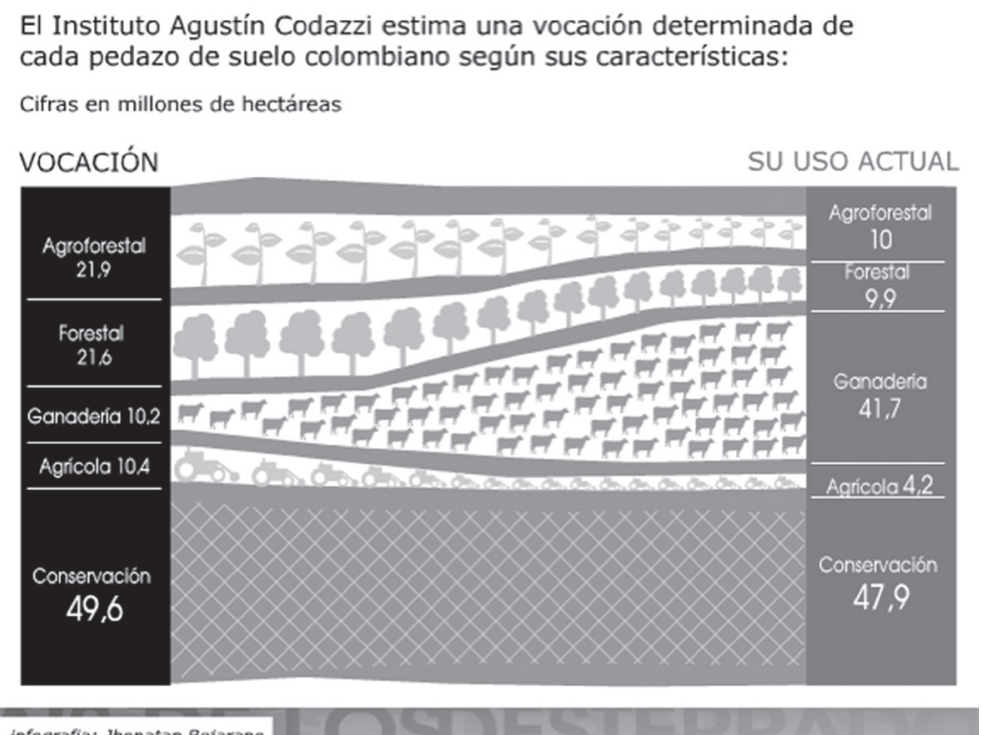

Fuente: "El país de los desterrados" (Maldonado, Gallón, \& Gutiérrez).

Según esta gráfica es evidente el cambio en los usos del suelo en las últimas décadas, en ella se evidencia que de los 41.7 millones de hectáreas destinadas a la ganadería sólo serían aptas para ésta la cuarta parte, es decir aproximadamente unos cuatro millones doscientas mil hectáreas. Mientras la ganadería aumenta, millones de hectáreas de bosques han sido arrasadas y zonas de vocación agrícola o a gro forestal han ido perdiendo espacio en medio de esta confluencia de crisis tanto social como económica. A la par, los programas de erradicación de cultivos ilícitos han presionado a campesinos y colonos de las zonas de amortiguación de algunas áreas naturales para ir colonizando zonas de alta importancia para la conservación. Tal es el caso de la cuenca alta y media del río Inírida que hace parte de la Reserva Nacional Natural Nukak, que en las últimas tres décadas ha continuado con el avance de la frontera cocalera, desestabilizando tanto la biodiversidad de la región como las comunidades indígenas que la habi$\tan$ (Cueto, 2010). Luego, las mismas dinámicas tradicionales de violencia hacen que surjan nuevos desplazamientos y que algunas de estas familias busquen albergarse en zonas más apartadas. Es una espiral constante, donde los problemas no resueltos de la concentración de la propiedad, la falta de una reforma agraria integral y la ausencia del Estado en términos de generación de políticas, acompañamiento técnico e inversión de capital están poniendo en peligro nuestra biodiversidad.

La situación ambiental de Colombia en vez de ser una prioridad dentro de las políticas de desarrollo, sigue siendo un discurso vacío que acompaña políticas pero que en la práctica privilegia sectores como el minero - energético que evidentemente son poco sostenibles. Es 
necesario reconocer que existe una gran responsabilidad del Estado en los procesos de colonización durante todos los periodos históricos, ya que su ausencia ha sido notoria y ha dejado que el desarrollo económico del país quede en manos del libre juego de las fuerzas del mercado (tradición - tenencia de la tierra tradicional). Esas fuerzas del mercado han contribuido a que los diferentes actores que han hecho presencia en estas zonas ejerzan un tipo de "capitalismo salvaje" en donde se pretenden obtener los mayores beneficios con los menores costos posibles, pero con muchas externalidades negativas en materia de impactos al medio ambiente y de los costos sociales que le ha implicado a este país esta prolongada guerra. Evidencia de este planteamiento, lo constituyen el exterminio de la población indígena en las épocas de la explotación de la quina, la tagua, el caucho y los recientes miles de asesinados y desaparecidos en las zonas de proliferación de los cultivos de coca.

Antes de que el Estado hiciera presencia en estas zonas de colonización, el uso de la fuerza había sido la manera de ejercer control sobre estos territorios desde los diferentes actores que han hecho parte de estos procesos, esto es evidente en la intensidad de explotación de los recursos naturales y de explotación de las comunidades indígenas y de colonos. Según Vieco (1995), al no existir una mediación del estado en el mercado y la sociedad civil, el resultado es que los problemas se resuelven por la vía de las armas y se genera una sociedad acostumbrada a regular los problemas derivados de las relaciones sociales y políticas entre los diferentes actores sociales, por medios violentos. Al respecto el autor escribe:
Lo que justifica la existencia de un Estado moderno es el ejercicio del monopolio del uso legitimo de la fuerza. ... La función básica del uso legitimo de la fuerza, se fundamenta en garantizar la prestación de un servicio público, cual es la protección y salvaguarda de la vida, honra y bienes de los ciudadanos, sin distinción alguna. Cuando el estado es incapaz de garantizar estos principios básicos, ese vacio es llenado por otros actores con mayor poder $y / o$ influencia que éste. Es el caso por el que atraviesan la totalidad de las zonas de bosque húmedo tropical, donde se localiza la mayor parte del proceso de colonización actual.

La ausencia del estado y el libre juego de las fuerzas del mercado han ocasionado profundos cambios en la estructura social, económica y politica de las regiones de colonización.

Esta sociedad excluyente y antidemocrática genera éxodo de los habitantes que no están de acuerdo con los nuevos criterios sociales y no permite el establecimiento de otras personas que no se identifiquen con sus postulados antidemocráticos. Mientras no exista una presencia estatal que refuerce el trabajo adelantado por organizaciones de la sociedad civil y de la Iglesia, no será posible establecer una paz que proporcione estabilidad al proceso de colonización (Vieco, 1995).

Durante las dos últimas décadas del siglo XX y la primera del siglo XXI, la colonización se ha implementado bajo la influencia de dos factores: el narcotráfico, a través de la compra de tierras y la conformación de estructuras de poder que modifican las dinámicas sociales en 
las zonas de colonización para poder expandir su dominio en estos territorios, y la migración de campesinos, colonos, indígenas y desplazados de la violencia hacia diferentes frentes de la colonización, perpetuando la confrontación directa de los diferentes actores armados.

Hoy en día, las áreas con mayor intensidad de conflicto coinciden a grandes rasgos con las zonas de colonización. Juan José Vieco afirma que es posible distinguir cuatro grandes regiones de colonización:

Costa atlántica, las áreas de las cuencas altas de los ríos Sinú, San Jorge y la zona de Urabá. b) Interior del pais: Magdalena Medio. c) Cuenca del pacifico. d.) Ecosistema Andino - Amazónico y Andino orinocense e inicio de las llanuras amazónica y orinocense.

A partir de esta zonificación macro, es posible establecer las áreas de mayor dinamismo colonizador, las cuales son: Bajo Calima, Casanare, Bajo cauca y nordeste Antioquenoo, Bota Caucana, Cuencas de los ríos Atá y Siquila (Tolima, Trapecio Amazónico, San José del Palmar - Condoto, Nóvita y Tadó (Chocó, Ariari-Guayabero, Valles Altos de los ríos Sinú y San Jorge, Magdalena Medio, Guaviare - El Retorno, Putumayo-Medio, Cuenca del Rio Micay (Cauca), Samacá - Tame, Urabá Antioqueño - chocoano, La Mojana, Costa pacífica nariñense, Miraflores (Guaviare), Costa pacifica chocoana, Catatumbo (Santander del Norte) (Vieco, 1995).

Actualmente la expansión de la frontera agrícola se concentra en el suroriente del país (Amazonía - Orinoquía) debido a varios factores entre los que se cuentan las presiones por parte del Ejército para controlar las zonas tradicionales de cultivos ilícitos lo que ha hecho que los procesos colonizadores se internen en zonas selváticas en donde los controles por el cultivo de coca (única actividad rentable en estas zonas) son menores.

Las problemáticas sociales que viven los pobladores de estas zonas que demandan servicios básicos que el Estado debería garantizar, se enfrentan a condiciones de falta de gobernabilidad y la limitación de encontrarse en muchos de los casos en zonas de conservación como Reservas Forestales de la Nación o Parque Nacional. La falta de alternativas a los cultivos de la coca pues son ocupantes ilegales que difícilmente pueden acceder a programas de gobierno.

Así que en este momento de la historia se repite el ciclo de la economía de la coca que aunque lleva varios años manteniendo un margen de ganancia mucho menor, aún sigue siendo el cultivo más rentable y con una cadena productiva garantizada desde la producción hasta la comercialización. A pesar de que continúa ocupando uno de los primeros renglones de ingreso de la economía de estas regiones, que en sus zonas ya vivieron la experiencia de la crisis de la producción de la hoja, estas zonas se encuentran con altos índices de desempleo porque muchos no han podido encontrar en los cultivos tradicionales la compensación económica que recibían en las épocas de bonanza. $\mathrm{La}$ actividad cocalera genera un margen de ganancia comparable con el de la ganadería que se utiliza como una forma de ahorro para los trabajadores de la coca, aunque esto es ha disminuido sustancialmente pues el mayor número de personas son jornaleros que se insertan en el 
círculo vicioso de las economías de bonanza, de los gastos suntuosos y el consumo de artículos de moda.

Por esto, muchas personas deciden aventurarse nuevamente formando poblados muy retirados de los cascos urbanos con altos grados de población flotante, que normalmente son controlados por grupos ilegales que controlan a su vez el mercado de la coca, ampliando la frontera agrícola y generando impactos de grandes dimensiones ambientales pues como es sabido estás áreas amazónicas tienen unos ecosistemas muy frágiles que se han afectado debido a los incendios forestales, a la utilización de insumos químicos que contaminan las fuentes de aguas y ante todo del daño por la acción antrópica que significa la constante deforestación de los bosques para colonizar nuevas áreas. Hay que reconocer que los espacios de colonización que se convirtieron en el ámbito de producción de los cultivos con fines ilícitos tienen altas rentabilidades para quienes lo procesan y comercializan en el exterior, mientras empobrecen a quienes producen la materia prima y deterioran el territorio donde se realiza la producción primaria.

Lo anterior evidencia que solamente en la medida en que se contribuya a dar respuesta a todas las necesidades y expectativas de las comunidades que habitan las zonas en peligro de colonización, se podrán diseñar políticas coherentes de colonización y de freno a la expansión agrícola. Humberto Rojas menciona que hay que atender y no hostilizar a la colonización existente, lo que es muy distinto de fomentar procesos colonizadores, para que como resultado deseable, no sólo se disminuya el impacto ambiental negativo sino que, primordialmente, se rescaten seres humanos de condiciones reproducidas de miseria, enfermedad y auto explotación a las que están siendo sometidas (Rojas Ruiz, 1990).

La colonización caótica ha sido un factor determinante en la creación y expansión de la frontera agrícola en nuestro país, pero hay que reconocer que en cada etapa histórica de su conformación, transformación y obedeciendo también a las políticas de desarrollo nacional han existido unas características y condiciones concretas que determinan aspectos sociales, económicos y políticos de nuestra configuración como nación. Teniendo en cuenta que la gran mayoría de estos procesos se han dado de manera no planificada, promovidos por el mismo gobierno como resultado inicialmente de un déficit fiscal que debía sanear y luego con un propósito fundamentado en el poder desarrollar una producción agropecuaria que le permitiera participar de manera activa en los mercados internacionales, se puede concluir que nuestra carrera para alcanzar el anhelado desarrollo ha contribuido con la ampliación de la frontera agrícola en la mayoría de zonas de nuestro país, lo que ha traído consigo la degradación de un elevado porcentaje de nuestros bosques y áreas naturales.

Lo anterior evidencia que solamente en la medida en que se contribuya a dar respuesta a todas las necesidades y expectativas de las comunidades que habitan las zonas en peligro de colonización, se podrán diseñar políticas coherentes que frenen la colonización y la expansión agrícola. Para ello es necesario tener en cuenta algunos de los elementos necesarios que expone Antonio García en su texto "Modelos operacionales de reforma agraria y desarrollo rural en América latina" (1982) y que en este texto se complementan para diseñar las fases de esa nueva propuesta de desarrollo: 
1. Lograr motivar a las comunidades a generar procesos de movilización social que de manera pacífica y concertada propongan un nuevo modelo de desarrollo desde sus necesidades y contextos particulares.

2. La implantación desde el Estado de una nueva lógica del desarrollo que modifique la tendencia de crecimiento económico y que transforme nuestros imaginarios sociales a otros donde se privilegie el desarrollo integral de las comunidades. Para esto se requiere: a. La conformación de nuevas y eficaces formas de participación popular. b. Que la sociedad empiece a ejercer control sobre los recursos básicos existentes en cada sociedad y c. Planificar de manera estratégica el proceso y no únicamente como un programa de cada gobernante de turno, sino como política de Estado.

3. Finalmente una transformación de la conciencia social en búsqueda de un proyecto colectivo de nación, en donde a partir de propuestas de comunicación y educación, se permita a la sociedad establecer nuevas maneras de dialogar desde saberes distintos y cosmovisiones diversas.

En conclusión, la tendencia que se ha dado en los últimos años a reproducir desplazamientos forzado que fomenten el desarraigo de miles de colombianos seguirá contribuyendo en buena medida a ampliar la frontera agrícola e incluso a amenazar las zonas de conservación del país. Esas nuevas migraciones ocurren entonces dentro de las estructuras productivas que componen las "macro-regiones", dinamizadas por el comportamiento de la economía y empujadas por las acciones violentas que dirigen los grandes intereses económicos y políticos en torno a los recursos territoriales y el control de la población. (Fajardo, 2002). Por lo tanto, mientras no se den estrategias que se dirijan a estabilizar y poner límites a la frontera agrícola, este panorama seguirá siendo un círculo vicioso que cada día deje más víctimas y menos recursos de nuestro capital natural. Es imperioso reconocer todos los factores que han influido en esta lamentable situación y plantear respuestas integrales que conduzcan a una verdadera reforma agraria mucho más equitativa y reparadora de los históricos y continuos atropellos que se han cometido contra los sectores más desprotegidos de las zonas rurales de nuestro país.

\section{Referencias}

I. Cueto, J. (2010). Escenarios de la colonización en la cuenca alta y media del río Inírida. Revista Colombiana de Sociología, 33 (1).

2. Etter, A., \& Sarmiento, A. (2009). La reconfiguración del espacio rural en Colombia: Entre la expansión de la frontera agropecuaria y la intensificación de la agricultura. In F. LOZANO, \& J. G. FERRO (Eds.), Las configuraciones de los territorios rurales en el siglo $X X I$. Bogotá, Colombia: Javegraf.

3. Fajardo, D. (2002). Para sembrar la paz hay que aflojar la tierra. Bogotá: Universidad Nacional de Colombia.

4. Fajardo, D. (1989). La colonización de La Macarena en la historia de la frontera agraria En: "Yo le digo una de las cosas... La colonización de la reserva de $L a$ Macarena". Bogotá: Corporación Araracuara. Fondo FEN. 
5. García, A. (1982). Modelos operacionales de reforma agraria y desarrollo rural en América Latina. San José, Costa Rica: IICA.

6. Gómez Merlano, A. (1985). La colonización en Colombia: Características y proyecciones. Bogotá: Instituto Colombiano de la Reforma Agraria.

7. Instituto Colombiano de Reforma Agraria. (1985). La Colonización en Colombia: Características y proyecciones. Conferencia pronunciada por el doctor Antonio Gómez Merlano, gerente general del Incora en el IV Congreso Nacional de Ecología., (p. 23). Cartagena.

8. Legrand, C. (1988). Colonización y protesta campesina en Colombia 1850-1950. Bogotá: Universidad Nacional de Colombia.

9. López Hernández, C. (2010). "La refundación de la patria, de la teoría a la evidencia" en Y refundaron la patria... De cómo mafiosos y politicos reconfiguraron el Estado colombiano. Bogotá, Colombia: Random House Mondadori.

ıo.Maldonado, J. C., Gallón, A., \& Gutiérrez, C. (s.f.). El país de los desterrados. Recuperado el 16 de 05 de 2011, de El espectador. com: http://static. elespectador.com/especiales/2010/09/ d16895bf8bcc04402740d5f0eff6a$\mathrm{dad} /$ index.html

i I.Márquez, G. (2001). Medio ambiente $y$ violencia en Colombia: una hipótesis. Análisis Político (44), 58-76.

I2.Medina, C. (1990). Autodefensas, paramilitares y narcotráfico en Colombia. Bogotá: Editorial Documentos periodísticos.

I3. Meertens, D. (Agosto de 2010). El pais de los desterrados - Memorias del despojo. Recuperado el 17 de Mayo de 2011, de elespectador.com: http:// static.elespectador.com/especiales/2010/09/d16895bf8bcc0440274 0d5f0eff6adad/m_columnistas.html I4. Molano, A. (1987). Selva adentro. Una historia oral de la colonización del Guaviare. Bogotá.: El Áncora Editores.

I 5.Mora, L., Cubides, F., \& Jaramillo, J.E. (1987). Colonización, coca y guerrilla. Bogotá: Alianza Editorial Colombiana.

I6. Neef, M. (1994). Desarrollo a escala humana: Conceptos, aplicaciones y algunas reflexiones. Montevideo, Uruguay: Nordan Comunidad - Icaria Editorial S.A.

I7.Palacio Castañeda, G. (2006). Fiebre de tierra caliente. Una historia ambiental de Colombia 1850 - 1930. Bogotá, Colombia: ILSA.

I 8. Parsons, J. (1997). La colonización antioqueña en el occidente de Colombia. . Bogotá: Banco de la república - El Áncora Editores.

19.Parsons, J. (1996). Urabá: Salida de Antioquia al Mar. Geografía e historia de su colonización. Bogotá: El Áncora Editores.

2o. Rojas Ruiz, H. (1990). Economía campesina y uso de los recursos naturales en zonas de colonización (continuación) en Livestock Research for Rural Development. Volume 2, Número 1.

2г.Trujillo, A., \& Castaño, P. (Directors). (1992). La ley del Monte [Motion Picture].

22.Vieco, J.J. (1995). El proceso de colonización en Colombia durante el último decenio. Bogotá: Conferencia Episcopal de Colombia. 